\title{
$\mathrm{Ca}$ 첨가 반응고 $\mathrm{AZ} 31$ 마그네슘 합금의 재가열에 따른 미세조직 변화
}

\author{
김희경 · 성봉학 · 반근호 · 김대환 · 성영록* • 임수근 \\ 경상대학교, $i$-Cube Center, 공학연구원, *희성정밀주식회사
}

\section{Microstructure Evolution of Semi Solid AZ31+(Ca) Magnesium Alloys during Reheating Process}

\author{
Hee-Kyung Kim, Bong-Hak Seong, Guen-Ho Van, Dae-Hwan Kim, Yeong-Rok Seong*, and Su-Gun Lim ${ }^{\dagger}$ \\ $i$-Cube Center, Engineering Research Institute, Gyeongsang National University, Jinju 660-701, Korea \\ *HEESUNG PRECISION. Ltd. Changwon 641-120, Korea
}

\begin{abstract}
In this study, we are aimed to prevent grain growth of semi-solid AZ31 magnesium alloys during reheating process. The semisolid $\mathrm{AZ3} 1+(\mathrm{Ca})$ billets were investigated by using metallographic analysis, X-ray diffraction, scanning electron microscopy and energy dispersive spectroscopy in order to elucidate the effect of $\mathrm{Ca}$ addition during reheating process. The grain growth of semisolid $\mathrm{AZ31}+(\mathrm{Ca})$ billet was reduced with increasing $\mathrm{Ca}$ content during reheating. The grain size of $\mathrm{AZ} 31+(\mathrm{Ca})$ billet decreased with increasing volume fraction of $\mathrm{Al}_{2} \mathrm{Ca}$ particles. The grain growth rate constant $\mathrm{K}$ calculated by Oswald ripening LSW theory in AZ31+1.5wt.\% Ca billet was the lowest 129 .
\end{abstract}

Key words : AZ31 Mg alloy, Cooling plate, Semi-solid metal, Reheating, Microstructure.

(Received February 21, 2011 ; Accepted March 27, 2011)

\section{1. 서 론}

최근, 환경 규제 강화로 인한 $\mathrm{CO}_{2}$ 저감 정책으로 에코(eco) 및 고 효율적 수송기기의 생산을 위한 많은 연구들이 진행되고 있고 기존의 무거운 철계 부품을 대신하여 경량 소재를 사용함 으로써 무게절감을 위한 경량화가 필수적인 분야에서의 수요가 증가하고 있다. 특히, 저 밀도 및 고 비강도 특성을 지니는 마 그네슘 합금은 수송기기의 대부분을 차지하는 철계 부품을 대 신할 경우, 기존의 수송기기 중량을 감소시킬 수 있어 더욱 효과적이다. 하지만, 마그네슘 합금은 상온에서의 낮은 성형성 ( $\mathrm{HCP}$ 결정구조)으로 인해 부품의 적용에 많은 한계를 지니고 있어 이를 대체할 방안으로 반응고/반용융 성형법이 있다.

반응고/ 반용융 성형법은 금속 슬러리의 틱소트로픽 성질을 이용하여 고액 공존 영역에서 금속 재료를 주조 및 성형하는 방법으로 유동성이 향상되어 복잡한 형상의 성형이 가능하며,
압출 압력의 감소로 인하여 다이스의 손상을 감소시키는 장점 이 있다[1-4]. 그러나 반용융 성형 시 고액공존영역까지 재가열 하는 공정을 거치게 되며 재가열 과정에서 빌렛의 결정립이 성장하고, 산소와 반응하여 산화 문제가 발생하게 된다. 내 산 화 특성 개선을 위해서는 보호가스를 적용하는 방안과 합금원 소를 첨가하는 방안 등이 있으며 그 중 합금원소를 첨가하는 방안은 보호가스를 도포하기 위한 별도의 부가장치를 필요로 하지 않기 때문에 공정상 여러 장점이 있다. 마그네슘 합금 용탕의 내 산화 특성 개선 효과가 있는 것으로 알려진 첨가 원소로는 $\mathrm{Be}, \mathrm{Ca}$ 등이 있으며, 특히 $\mathrm{Ca}$ 첨가 효과가 탁월한 것 으로 보고되고 있다[5-7]. 또한 $\mathrm{Mg}-\mathrm{Al}$ 계 합금계에 $\mathrm{Ca}$ 을 첨가 할 경우 $\mathrm{Al}_{2} \mathrm{Ca}$ 상의 생성으로 결정립계 및 아결정립계에 전위 의 이동을 억제하여 결정립 미세화와 결정립 성장 억제 효과가 있는 것으로 보고되고 있다[8-12].

따라서 본 연구에서는 첨가 원소를 이용하는 합금화법을 통

'Corresponding author: Su-Gun Lim

[Tel: +82-55-772-1664, E-mail : suglim@gnu.ac.kr] 
해 마그네슘 합금의 내산화성을 개선함으로써 마그네슘을 대기 중에서 용해하였고, 마그네슘 합금의 강도 및 가공성 향상을 위해서 경사냉각판법을 사용하여 반응고 빌렛을 제조하였다. 또 한 합금을 제조한 후 재가열 공정을 통해 고액공존 영역에서의 미세조직 변화를 알아보고자 하였다.

\section{2. 실험 방법}

본 연구에 사용된 $\mathrm{AZ31}+(\mathrm{Ca})$ 합금은 $\mathrm{AZ31}$ 합금과 $\mathrm{Al}-90$ $\mathrm{wt} \% \mathrm{Ca}$ 모합금을 이용하여 $\mathrm{Ca}$ 을 각각 $0 \mathrm{wt} . \%, 0.5 \mathrm{wt} \%$, $1.0 \mathrm{wt} . \%, 1.5 \mathrm{wt} . \%$ 을 첨가하여 제조하였다. $\mathrm{AZ31}$ 합금을 전기저 항로에서 $700^{\circ} \mathrm{C}$ 의 온도로 1 시간 가열하여 완전용해 한 후 $\mathrm{Al}-$ $90 \mathrm{wt} . \% \mathrm{Ca}$ 모합금을 투입하여 10 분 등온 유지하였다. 용해 시 합금의 산화로 인한 용탕의 손실을 줄이기 위하여 $\mathrm{Ar}$ 가스 분 위기에서 실시하였다. 반응고 빌렛의 제조는 경사냉각판 방법을 이용하였으며, 완전 용해한 용탕을 주입온도 $650^{\circ} \mathrm{C}$, 냉각판의 각도 $50^{\circ}$, 냉각판의 길이 $200 \mathrm{~mm}$, 몰드예열온도 $570^{\circ} \mathrm{C}$, 유지 시간 $10 \mathrm{sec}$ 조건으로 제조 후 수냉하였다. 제조한 $\mathrm{AZ} 31+(\mathrm{Ca})$ 합금의 화학 조성은 Table 1에 나타내었다. 반용융 압출을 진 행하기에 앞서 고액공존영역까지 재가열하는 공정을 거치게 되 며 재가열시 미세조직변화는 반용융 압출에서 매우 중요하므로 재가열 온도와 재가열 시간에 따른 조직의 변화를 분석하였다. $\mathrm{Ca}$ 을 첨가하지 않은 $\mathrm{AZ31}$ 합금은 재가열 과정에서 산화가 발 생하게 되어 배제하였다. AZ31+ $(0.5 \sim 1.5 \mathrm{wt} \% \mathrm{Ca})$ 합금으로 재가 열 실험을 진행 하였으며, 제조한 빌렛을 $\Phi 50 \times 85 \mathrm{~mm}$ 크기 로 기계가공 하였다. 실제 빌렛의 온도변화를 확인하기위해 빌 렛 중심부에 K-Type열전대를 삽입하여 재가열시 온도변화를 측정하였다. 재가열시 빌렛의 액상율 측정을 위해서 DSC 분석 결과를 부분 적분법을 이용하여 계산하였다[13]. 재가열 실험은 $590^{\circ} \mathrm{C}$ 로 등온 유지되고 있는 전기저항로를 사용하였으며, 재가 열 온도는 액상율이 $10 \%, 23 \%$ 인 $560^{\circ} \mathrm{C}$ 와 $590^{\circ} \mathrm{C}$ 로 설정하였 다. 재가열시 각 온도조건에 따른 미세조직변화를 알아보기 위 해 수냉하여 미세조직을 관찰하였다. 반응고 빌렛과 재가열후의 미세조직 관찰을 위하여 시편 바닥으로부터 $30 \sim 40 \mathrm{~mm}$ 높이의 중앙부를 채취하였고, 이를 미세 연마한 후, $100 \mathrm{ml}$ 증류수와 $4 \mathrm{ml}$ 질산 $\left(\mathrm{HNO}_{3}\right)$ 을 혼합한 용액에 수초 동안 에칭 하여 광학 현미경으로 미세조직을 관찰하였다. $\mathrm{Ca}$ 을 첨가한 합금의 정출 상 관찰을 위하여 $\mathrm{X}$-선 회절 및 분광분석(EDS)을 이용하여 분석 하였다.

\section{3. 결과 및 고찰}

\section{1 반응고 빌렛의 제조에 미치는 $\mathrm{Ca}$ 의 영향}

Fig. 1은 각 합금의 액상선과 고상선을 알아보기 위해서 완 전 용해한 용탕을 단열 용기 내에서 서서히 공랭 시켜 시간에 따른 $\mathrm{AZ} 31+(\mathrm{Ca})$ 합금 용탕의 온도 변화를 나타낸 것이며, 각 합금의 고상선과 액상선을 Table 2에 나타내었다. AZ31합금의 경우 액상선 온도는 $632^{\circ} \mathrm{C}$, 고상선 온도는 $568^{\circ} \mathrm{C}$ 로 다른 합금 계에 비해 좁은 고·액 공존구간을 가지고 있었으며, AZ31+ $0.5 \mathrm{wt} . \% \mathrm{Ca}$ 합금의 경우 액상선 온도 $630^{\circ} \mathrm{C}$, 고상선온도는 $518^{\circ} \mathrm{C}$ 였고, $\mathrm{AZ} 31+1.0 \mathrm{wt} \% \mathrm{Ca}$ 합금의 경우 액상선 온도는 $628^{\circ} \mathrm{C}$, 고상선온도는 $518^{\circ} \mathrm{C}$ 였다. 그리고 $\mathrm{AZ} 31+1.5 \mathrm{wt} . \% \mathrm{Ca}$ 합 금의 경우 액상선 온도는 $626^{\circ} \mathrm{C}$ 고상선 온도는 $518^{\circ} \mathrm{C}$ 였다. $\mathrm{Ca}$ 첨가로 인해 고·액 공존구간이 넓어졌으며, 액상선의 온도 는 조성적 과냉에 의해 $\mathrm{Ca}$ 이 증가함에 따라 점차 낮아졌다. 한편 $\mathrm{Ca}$ 첨가한 합금의 고상선 온도는 $518^{\circ} \mathrm{C}$ 로 일정하였으며,

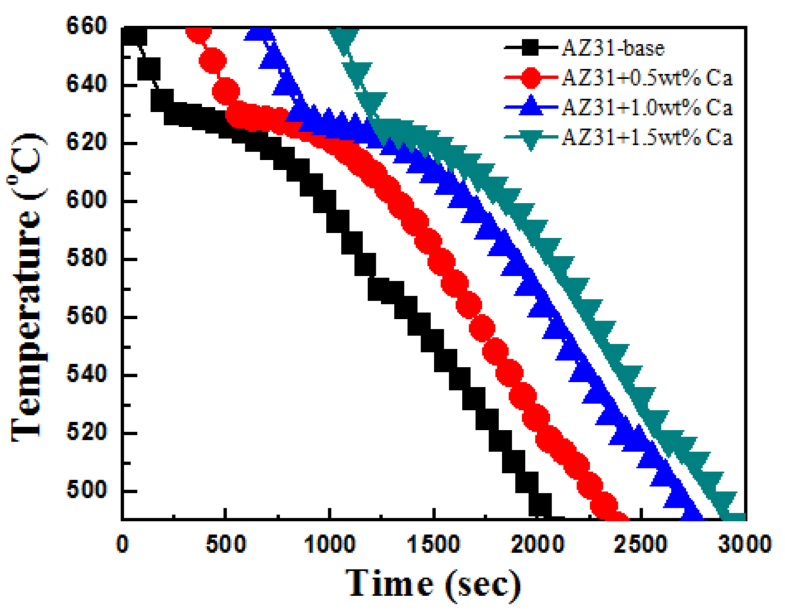

Fig. 1. Cooling curve of semi-solid AZ31+(Ca) billets.

Table 2. Liquidus and solidus temp. of $\mathrm{AZ} 31+(\mathrm{Ca})$ alloys $\left({ }^{\circ} \mathrm{C}\right)$.

\begin{tabular}{ccc}
\hline Alloys & Liquidus temperature & Solidus temperature \\
\hline $\mathrm{AZ} 31$ & 632 & 568 \\
$\mathrm{AZ} 31+0.5 \mathrm{Ca}$ & 630 & 518 \\
$\mathrm{AZ} 31+1.0 \mathrm{Ca}$ & 628 & 518 \\
$\mathrm{AZ} 31+1.5 \mathrm{Ca}$ & 626 & 518 \\
\hline
\end{tabular}

Table 1. Chemical composition of semi solid AZ31+(Ca) billets. (wt.\%).

\begin{tabular}{|c|c|c|c|c|c|c|c|c|}
\hline Alloys & $\mathrm{Al}$ & $\mathrm{Zn}$ & $\mathrm{Mn}$ & $\mathrm{Ca}$ & $\mathrm{Si}$ & $\mathrm{Cu}$ & $\mathrm{Fe}$ & $\mathrm{Mg}$ \\
\hline AZ31 & 3.49 & 0.82 & 0.41 & 0 & 0.07 & 0.08 & 0.06 & Bal. \\
\hline $\mathrm{AZ} 31+0.5 \mathrm{Ca}$ & 3.47 & 0.84 & 0.39 & 0.48 & 0.07 & 0.08 & 0.05 & Bal. \\
\hline $\mathrm{AZ} 31+1.0 \mathrm{Ca}$ & 3.49 & 0.78 & 0.42 & 0.98 & 0.07 & 0.08 & 0.06 & Bal. \\
\hline $\mathrm{AZ} 31+1.5 \mathrm{Ca}$ & 3.53 & 0.79 & 0.39 & 1.53 & 0.08 & 0.08 & 0.08 & Bal. \\
\hline
\end{tabular}


이는 $\mathrm{Mg}-\mathrm{Ca}$ 상태도[14]에서의 공정선의 응고온도가 $518^{\circ} \mathrm{C}$ 이므 로 $\mathrm{Ca}$ 첨가한 합금의 고상선 온도가 일정한 것으로 사료된다.

Fig. 2는 경사냉각판에 의해 제조된 반응고 $\mathrm{AZ} 31+(\mathrm{Ca})$ 빌렛 의 미세조직 관찰변화를 나타내었다. 경사냉각판법으로 제조된 모든 빌렛의 미세조직은 조대한 수지상의 초정이 아닌 미세하 고 구형에 가까운 형상의 초정을 가짐을 확인할 수 있었다. 제 조 후의 결정립의 크기는 55 60 $\mu \mathrm{m}$ 로 나타났으며 반응고 주 조시 냉각판에 초정이 유리되어 수지상이 적은 구형의 미세한 조직을 갖는 것이라고 사료되며, $\mathrm{Ca}$ 이 첨가됨에 따라 초정의 크기는 큰 변화가 없는 것으로 나타났다[15-18]. 일반적으로 주 조 시 $\mathrm{Ca}$ 이 증가함에 따라 조성적 과냉에 의해 핵생성을 유도 하여 결정립 미세화 역할을 하지만, 경사냉각판법을 이용한 반 응고 빌렛 제조에서는 경사냉각판에 의한 핵생성이 더 큰 것 으로 생각된다. 한편 $\mathrm{Ca}$ 을 첨가한 합금의 미세조직을 관찰한
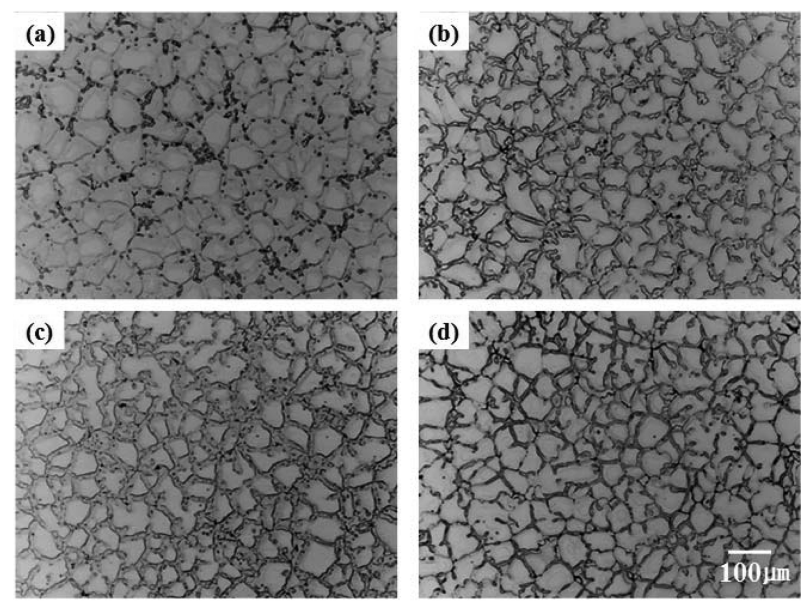

Fig. 2. Microstructures of semi-solid $\mathrm{AZ} 31+(\mathrm{Ca})$ billets made by cooling plate method ; (a) $0 \mathrm{wt} . \%$, (b) $0.5 \mathrm{wt} . \%$, (c) $1.0 \mathrm{wt} . \%$, (d) $1.5 \mathrm{wt} . \%$.
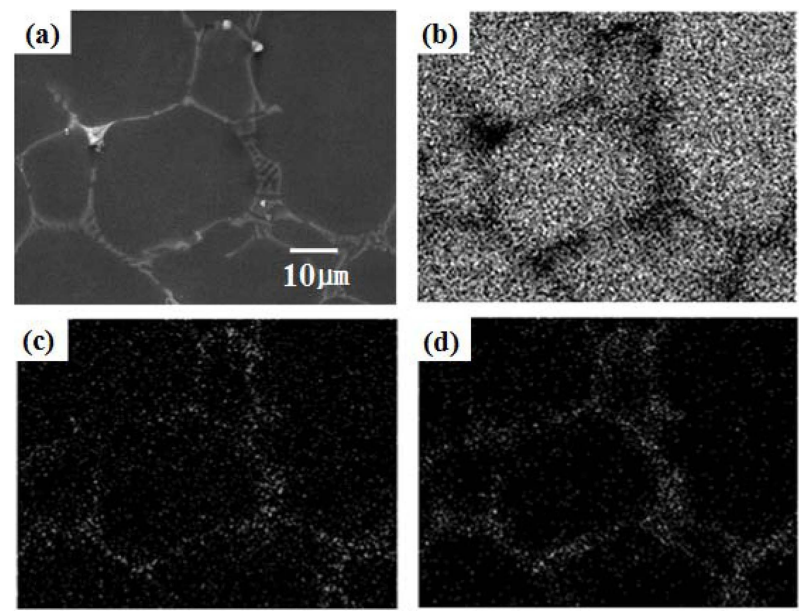

Fig. 3. EDS mapping of semi-solid AZ31+1.5wt.\%Ca; (a) SEM image, (b) $\mathrm{Mg}$, (c) $\mathrm{Al}$, (d) $\mathrm{Ca}$.
결과 공정계 부분의 변화를 확인할 수 있었으며, 정확한 분석 을 위해서 $\mathrm{SEM}$ 으로 관찰하였다.

Fig. 3은 AZ31+1.5wt.\% Ca 합금의 EDS Mapping 결과를 나타내었다. 결정립계를 이루고 있는 공정계는 라멜라층을 이루 고 있는 것을 알 수 있었다. Fig. 3의 Mapping 분석 결과를 보면 $\mathrm{Al}$ 과 $\mathrm{Ca}$ 이 결정립계를 따라 분포하고 있으며, $\mathrm{Al}-\mathrm{Ca}$ 화 합물을 형성하고 있을 것이라고 생각된다. H. Watanabe와 S. W. $\mathrm{Xu}$ [19-20]의 논문에 의하면 $\mathrm{Mg}-\mathrm{Al}-\mathrm{Ca}$ 합금의 결정립계가 라멜라층으로 형성되어져 있으며, 결정립계를 이루고 있는 것은 $\mathrm{Mg}_{2} \mathrm{Ca}, \mathrm{Al}_{2} \mathrm{Ca},(\mathrm{Mg}, \mathrm{Al})_{2} \mathrm{Ca}$ 상들로 구성되어져 있어 Fig. 3과 일치 한다고 본다.

Fig. 4는 제조한 $\mathrm{AZ} 31+(\mathrm{Ca})$ 빌렛의 XRD 분석 결과를 나타 내었다. $\mathrm{Ca}$ 의 첨가량이 $0.5 \mathrm{wt} . \%$ 이하의 경우는 $\mathrm{Mg}$ 상만 관찰 되었지만, $\mathrm{Ca}$ 의 첨가량이 $1.0 \mathrm{wt} . \%$ 이상 일때에는 $\mathrm{Al}_{2} \mathrm{Ca}$ 상과 $\mathrm{Mg}$ 상이 확인되었다. $\mathrm{Ca}$ 이 $0.5 \mathrm{wt} \%$ 첨가된 빌렛에서는 $\mathrm{Ca}$ 이 기지조직인 $\mathrm{Mg}$ 에 모두 고용된 결과라 생각되어진다. J. H. $\mathrm{Seo}$ 등[21]에 논문에 의하면 $\mathrm{Mg}$ 에 평형상태에서의 $\mathrm{Ca}$ 의 고용한 은 $1.34 \mathrm{wt} . \%$ 이고 평형상태가 아닌 경우에는 냉각속도나 제조 공법에 따라 차이가 나지만 약 $0.8 \mathrm{wt} . \%$ 정도가 마그네슘 기지 에 고용된다고 설명하였으며, 본 실험과 일치하였다.

\section{$3.2 \mathrm{Ca}$ 첨가한 반응고 빌렛의 재가열 특성}

반용융 압출에서 온도에 따른 고상과 액상의 비율은 매우 중요하다. 온도변화에 따른 액상율을 알아보기 위해 아르곤 분 위기에서 승온 속도 $10^{\circ} \mathrm{C} / \mathrm{min}$ 로 상온에서 $700^{\circ} \mathrm{C}$ 까지 $\mathrm{DSC}$ 분 석을 실시하였다. DSC 열분석 결과를 바탕으로 부분적분법 [13]을 이용하여 액상율을 계산하였으며, DSC 열분석 결과와 온도변화에 따른 액상율의 변화를 Fig. 5에 나타내었다. J. Dong 등과 S. Chayong 등[22,23]은 반용융 압출시 액상율 $10 \% \sim 25 \%$ 온도가 가장 적당한 조건이라고 보고 하였다. 따라서 본 실험에서는 계산되어진 액상율을 바탕으로 재가열시 $10 \%$,

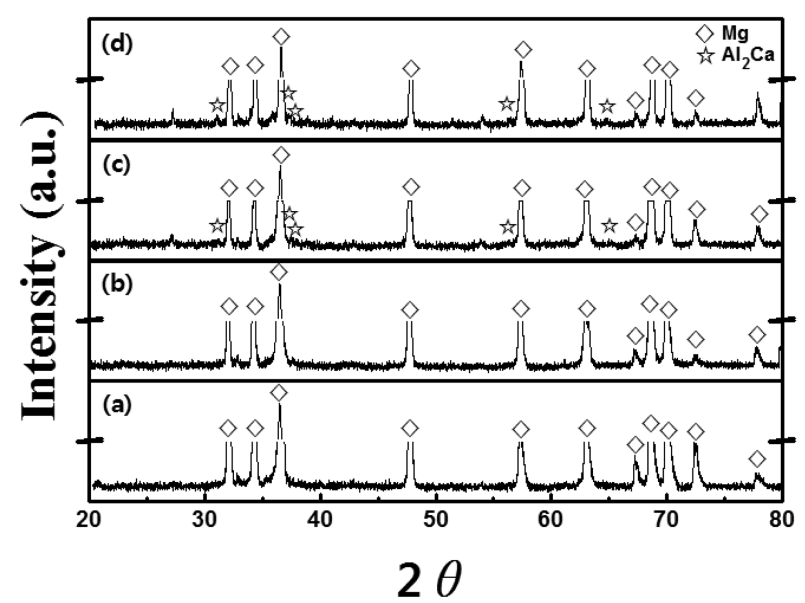

Fig. 4. X-ray diffraction patterns of semi-solid AZ31+(Ca) billets. ; (a) $0 \mathrm{wt} . \%$, (b) $0.5 \mathrm{wt} . \%$, (c) $1.0 \mathrm{wt} . \%$, (d) $1.5 \mathrm{wt} . \%$. 


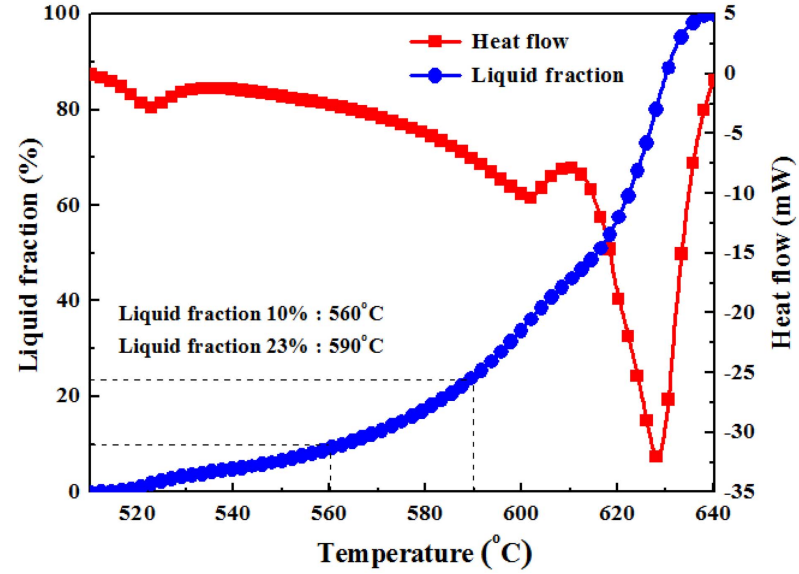

Fig. 5. DSC-TGA heating and liquid fraction curves of semi-solid $\mathrm{AZ} 31+0.5 \mathrm{wt} \%$ Ca billet at a constant heating rate of $10^{\circ} \mathrm{C} /$ min using the SDT Q600 TA Instruments.

$23 \%$ 를 가지는 온도인 $560^{\circ} \mathrm{C}$ 와 $590^{\circ} \mathrm{C}$ 를 재가열 온도로 설정하 였다. 액상율이 $25 \%$ 이상으로 초과되지 않도록 하기 위해서 전 기가열로의 온도를 $590^{\circ} \mathrm{C}$ 로 고정하였으며, 재가열시의 온도 상 승을 확인하기 위해 시편의 중심부에 K-Type 열전대를 삽입하 여 재가열시 실제 온도 변화를 측정하였으며, 그 변화를 Fig. 6에 나타내었다. 세 합금 모두 재가열 시간이 1800초로 도달 하였을 때 목표 액상율 $10 \%$ 인 $560^{\circ} \mathrm{C}$ 가 되었고, 2400 초가 경 과했을 때는 $590^{\circ} \mathrm{C}$ 가 되었다.

Fig. 7에 반응고 $\mathrm{AZ} 31+(\mathrm{Ca})$ 빌렛의 재가열 온도와 $\mathrm{Ca}$ 첨가 량에 따른 미세조직 변화를 나타내었다. 재가열전의 반응고 빌

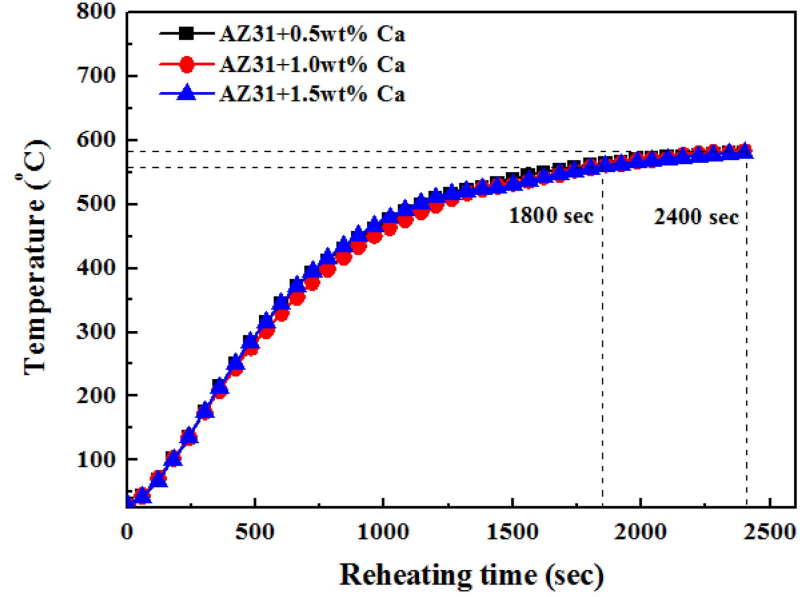

Fig. 6. Temperature change of semi-solid AZ31+(Ca) billets in heating process.

렛은 결정립 크기가 아주 미세한 조직이 관찰되었고, 빌렛온도 $560^{\circ} \mathrm{C}$ 일때는 결정립의 크기가 재가열전의 크기보다 성장하였고, 구형의 형상이 관찰 되었다. 그리고 빌렛온도 $590^{\circ} \mathrm{C}$ 일때는 $560^{\circ} \mathrm{C}$ 보다 더 결정립이 성장하였고, 재가열 온도가 높아짐에 따라 결정립 조대화 되는 경향을 나타내었다. S. K. Kim등 [24]의 논문에 의하면 마그네슘 합금이 구상의 형태를 유지하면 서 조대화 되는데 이는 마그네슘합금의 축비 $(\mathrm{c} / \mathrm{a}=1.624)$ 가 이 상적인 값 $(\mathrm{c} / \mathrm{a}=1.633)$ 에 가까운 $\mathrm{HCP}$ 구조이며 이방성이 없는 상태이기 때문이라고 설명하고 있다. 따라서 모든 임의의 방향 으로 성장이 일어나며 구형의 형태로 조대화 되는 것으로 생각

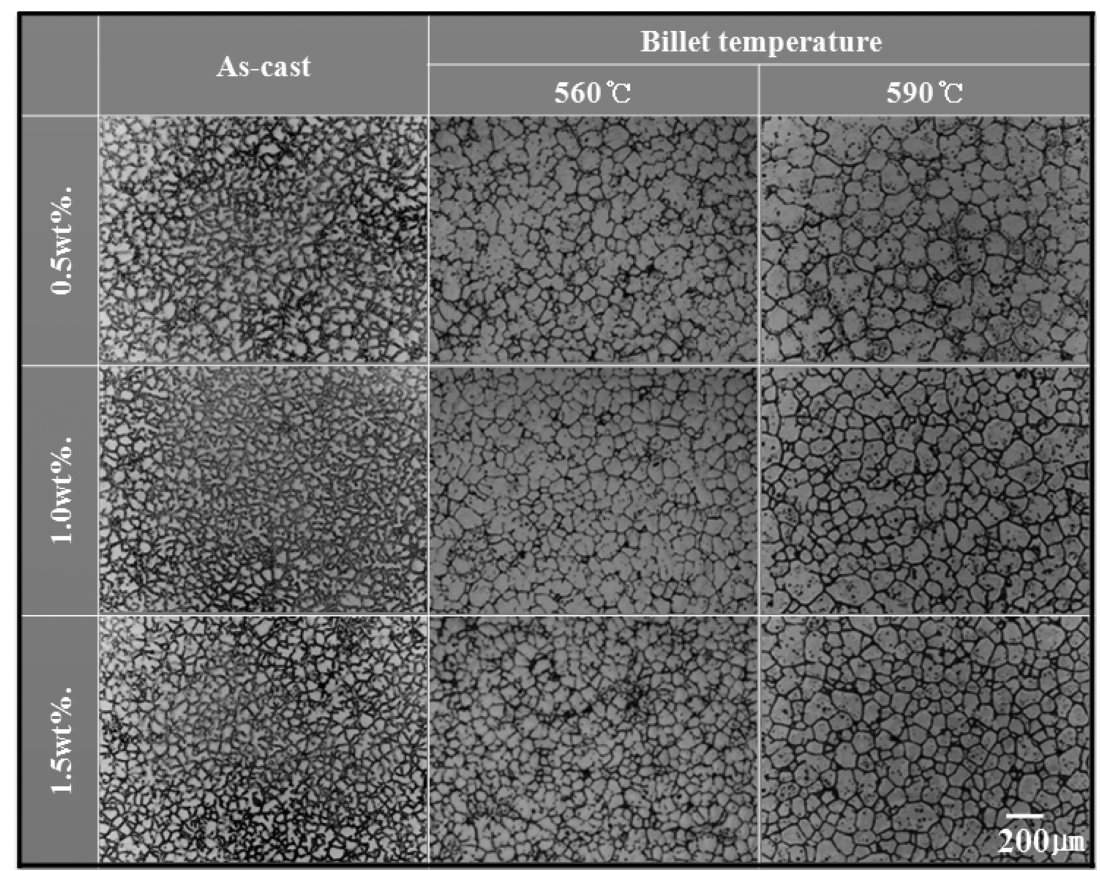

Fig. 7. Microstructures of semi-solid AZ31+(Ca) billets with increasing billet temperature as adding different amount of calcium. 


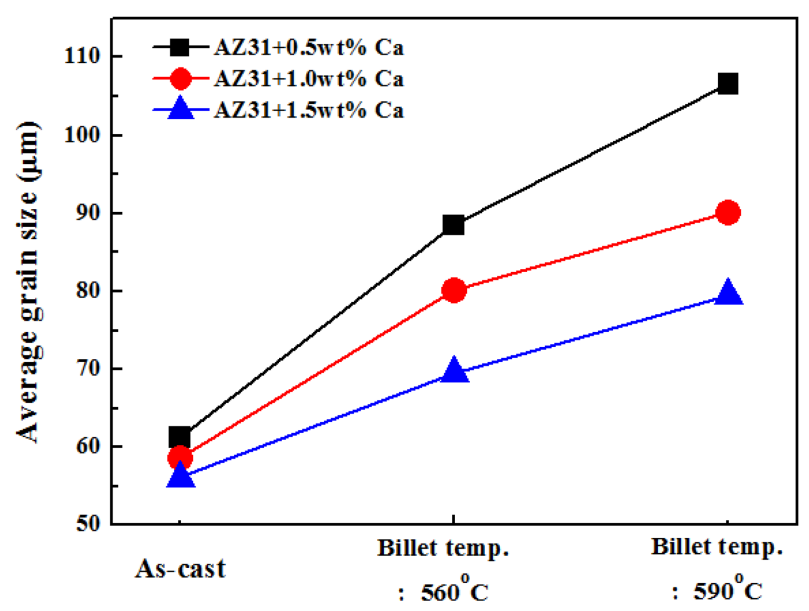

Fig. 8. Average grain size of semi-solid AZ31+(Ca) billets for each condition after reheating.

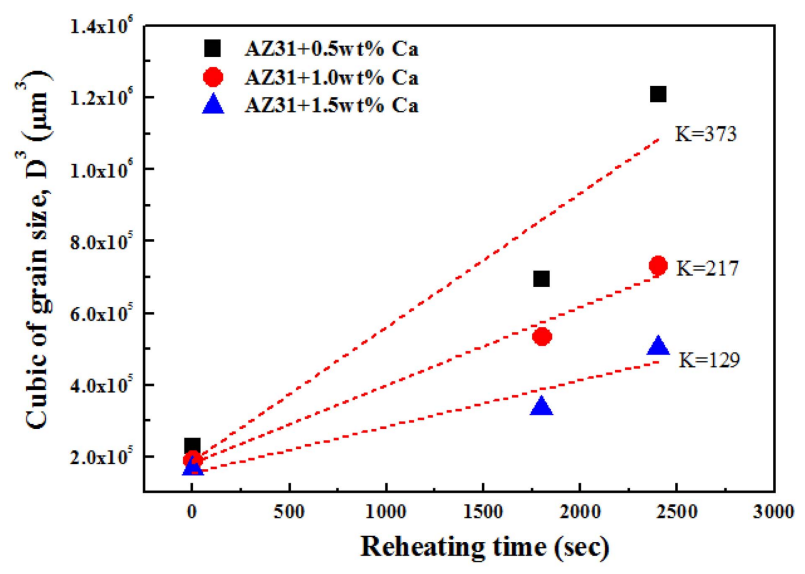

Fig. 9. Plot of $\mathrm{D}^{3}$ against reheating time.

된다. 하지만 $\mathrm{Ca}$ 의 첨가량이 증가함에 따라 결정립의 성장이 억제되었다. 이는 $\mathrm{Ca}$ 의 첨가로 인해 $\mathrm{Al}_{2} \mathrm{Ca}$ 화합물이 형성되어 결정립의 성장에 장애물로 작용된 것으로 생각된다.

Fig. 8은 반응고 $\mathrm{AZ} 31+(\mathrm{Ca})$ 빌렛의 재가열 온도와 $\mathrm{Ca}$ 첨가 량에 따른 평균 결정립의 크기를 나타냈다. $\mathrm{Ca}$ 이 $0.5 \mathrm{wt} . \%$ 첨 가 된 반응고 빌렛의 경우 재가열 전의 초정 $\alpha$ 의 크기는 61 $\mu \mathrm{m}$ 이며, 재가열 온도가 $560^{\circ} \mathrm{C}$ 일때 $88 \mu \mathrm{m}, 590^{\circ} \mathrm{C}$ 일때 $106 \mu \mathrm{m}$ 로 재가열 온도가 증가함에 따라 결정립의 크기는 성장 하였 다. $\mathrm{Ca}$ 이 $1.0 \mathrm{wt} . \%$ 첨가된 반응고 빌렛의 경우 재가열 전의 초정 $\alpha$ 의 크기는 $57 \mu \mathrm{m}$ 이며, 재가열 온도가 $560^{\circ} \mathrm{C}$ 일때 $81 \mu \mathrm{m}$, $590^{\circ} \mathrm{C}$ 일때 $90 \mu \mathrm{m}$ 로 $\mathrm{Ca}$ 을 $0.5 \mathrm{wt} . \%$ 첨가한 경우처럼 결정립성 장을 보였고, $\mathrm{Ca}$ 이 $1.5 \mathrm{wt} \%$ 첨가된 빌렛의 경우에서도 결정립 이 성장하는 것을 볼 수 있었다. 이는 재료 내부의 고상과 액 상간의 물질과 열 이동에 의한 조대화 현상으로 예측 할 수 있으며, 이를 정량화하기 위하여 Ostwald ripening[25-26]에 의 한 $\mathrm{LSW}(2)$ 이론 $[27,28]$ 에 적용시켜 보았다. $\mathrm{LSW}$ 이론은 모상 이 액상으로 이루어져 있을 경우 입자의 형상이 완전 구형이라
는 가정 하에 dilute system에서 적용이 되는 식으로, Lifshitz, Slyosow, Wagner가 이론적 해석을 하여 수식화 하였다.
$D^{3}-D_{0}^{3}=K t$
$\mathrm{K}$ : 조대화 상수
$\mathrm{t}:$ 유지시간
$\mathrm{D}_{0}: \mathrm{t}=0$ 에서의 고상입자의 평균 결정립크기
$\mathrm{D}: \mathrm{t}$ 에서의 고상입자의 평균 결정립 크기

위의 식을 이용하여 반응고 $\mathrm{AZ} 31+(\mathrm{Ca})$ 빌렛의 재가열 시간 에 따른 결정립 크기와 조대화 상수(K)값을 Fig. 9로 나타내었 다. 재가열 시간이 증가함에 따라 반응고 $\mathrm{AZ3} 1+(\mathrm{Ca})$ 빌렛의 결정립 크기는 점차 증가하였으며, $\mathrm{Ca}$ 첨가량에 따라 조대화 상수는 $373,217,129$ 로 감소하는 경향을 나타내었다. 조대화 상수의 감소는 결정립성장율의 감소를 나타내며, $\mathrm{Ca}$ 첨가량이 증가함에 따라 결정립 성장을 억제하는 것이라 생각된다.

\section{4. 결 론}

본 연구는 경사냉각판법을 이용한 반응고/반용융 성형법의 적용을 위한 기초단계로서 $\mathrm{Ca}$ 첨가한 반응고 마그네슘 합금의 재가열시 미세조직 변화를 관찰하였으며, 다음과 같은 결론을 얻었다.

1) 경사 냉각판법에 의해 제조된 반응고 마그네슘 합금들은 일반주조의 수지상에 비해 구형의 결정립을 가지는 조직을 관 찰할 수 있었으며, $\mathrm{Ca}$ 첨가에 의한 조성적 과냉보다 경사냉각 판법에 의한 영향이 더 크게 나타나 결정립의 크기가 차이나지 않았다.

2) 반응고 $\mathrm{AZ} 31+(0.5 \sim 1.5 \mathrm{wt} \% \mathrm{Ca})$ 마그네슘 빌렛의 Mapping 분석 결과 $\mathrm{Al}, \mathrm{Ca}$ 이 결정립계를 따라 분포하고 있었으며 라멜 라층을 이루고 있음을 확인하였다. 한편, 반응고 AZ31+(0.5 $1.5 \mathrm{wt} \% \mathrm{Ca}$ ) 마그네슘 빌렛의 $\mathrm{XRD}$ 분석결과 $\mathrm{Ca}$ 의 첨가량이 $1.0 \mathrm{wt} . \%$ 이상 일 때 $\mathrm{Al}_{2} \mathrm{Ca}$ 상과 $\mathrm{Ca}$ 상이 확인되었다.

3) 반응고 $\mathrm{AZ} 31+(0.5 \sim 1.5 \mathrm{wt} \% \mathrm{Ca})$ 마그네슘 빌렛의 재가열 시 시간이 증가함에 따라 빌렛의 결정립 크기는 점차 증가하였 으며, $\mathrm{Ca}$ 의 첨가량이 증가함에 따라 조대화 상수는 373,217 , 129 로 감소하는 경향을 나타내었다.

\section{감사의 글}

본 논문은 지식경제부의 WPM (World Premier Materials) 사업(No.10037928)을 수행하는 수송기기용 초경량 $\mathrm{Mg}$ 소재 사업단의 연구비 지원에 의하여 연구되었습니다.

\section{참고문헌}

[1] Atkinson H. V., Modelling the semisolid processing of 
metallic alloys, Prog Mater Sci, 50 (2005) 341-412

[2] Czerwinski F., Size evolution of the unmelted phase during injection molding of semisolid magnesium alloys, Scripta Mater, 48 (2003) 327-331

[3] Czerwinski F., On the generation of thixotropic structures during melting of $\mathrm{Mg}-9 \% \mathrm{Al}-1 \% \mathrm{Zn}$ alloy, Acta Mater, 50 (2002) 3265-3281

[4] Z. Fan., Semisolid metal processing, Int. Mater. Rev., 47(2) (2002)

[5] B. H. Choi, B. S. You, W. W. Park, I. M. Park, Oxidation Behaviors of Ca Containing AZ91 Magnesium Alloys, J. Kor. Inst. Met. \& Mater, 42(8) (2004) 673-678

[6] B. S. You, M. H. Kim, W. W. Park, I. S. Chung, Oxidation Behaviors of Molten Magnesium Containing Calcium, J. Kor. Inst. Met. \& Mater, 39(4) (2001) 446-450

[7] S. L. Cheng, G. C. Yang, J. F. Fan, Y. J. Li, Y. H. Zhou, Effect of $\mathrm{Ca}$ and $\mathrm{Y}$ additions on oxidation behavior of AZ91 alloy at elevated temperatures, Trans. Nonferrous Met. Soc. China, 19 (2009) 299-304

[8] J. H. Kim, N. E. Kang, C. D. Yim, B. K. Kim, Effect of calcium content on the microstructural evolution and mechanical properties of wrought $\mathrm{Mg}-3 \mathrm{Al}-1 \mathrm{Zn}$ alloy, Materials Science and Engineering A, 525 (2009) 18-29

[9] C. D. Yim, B. S. You, S. H. Kim, J. S. Lee, W. C. Kim, Hot Rolling Properties of Homogenized AZ31-xCa $(\mathrm{x}=0 \sim 2.0$ wt.\%) Gravity Cast, J. Kor. Inst. Met. \& Mater, (2004) 521529

[10] Q. Jin, J. P. Eom, S. G. Lim, W. W. Park, B. S. You, Effect of $\mathrm{Ca}$ addition on grain refinement and mechanical properties of AZ31 magnesium alloy, J. of the Korea Foundrymen's society, 23(5) (2003) 251-256

[11] J. P. Eom, S. K. Jeong, S. G. Lim, H. T. Shin, D. S. Jeong, Grain refinement and mechanical properties of AM60 Mg alloy by $\mathrm{CaCN}_{2}$ addition, J. of the Korea Foundrymen's society, 18(4) (2003) 383-388

[12] J. H. Jun, B. K. Park, J. M. Kim, K. T. Kim, W. J. Jung., Microstructures and Mechanical Properties of AZ31$(0 \sim 0.5 \%) \mathrm{Ca}$ Alloys, J. of the Korean Society for Heat Treatment, (2004) 299-304

[13] E. Tzimas, A. Zavallangos., Evaluation of volume fraction of solid in alloys formed by semisolid processing, J. of Materials science, 35 (2000) 5319-5329

[14] Edward H., Vol.3 Alloy Phase Diagram, ASM handbook, ASM international, (1992) 555

[15] D. H. Kim., Y. R. Sung., S. Y. Shim., S. Y. Lee., K. S. Kim., S. G. Lim., J. Kor. Foundarymen's Soc. The Microstructures and hot extrudability of semi-solid AM100A magnesium alloy fabricated by cooling plate, 29(3) (2009) 144-149

[16] D. H. Kim., S. Y. Shim., Y. H. Kim., S. G. Lim., J. Kor. Foundarymen's Soc. RRA Treatment of Semi-Solid Al-ZnMg-Cu Al alloy Fabricated by Cooling Plate, 29(6) (2009) 265-269

[17] H. W. Park., D. H. Kim., S. Y. Shim., H. K. Kim., B. H. Seong., C. O. Choi., S. G Lim., J. Kor. Foundarymen's Soc. The Effect of $\mathrm{Ca}$ Addition on the Grain Growth Inhibition During Reheating Process of Al-Zn-Mg Al Alloys for Thixoextrusion, 31(6) (2011) 347-353

[18] S. Y. Shim., D. H Kim., Y. R Seong., S. G Lim., Statistical Analysis for Influence of Factors on Morphological Evolution in Semi-Solid Al-6Zn-2.5Mg-0.5Cu Alloy by Cooling Plate Method, Materials Transactions, 52(5) (2011) 862-867

[19] S. W. Xu, N. Matsumoto, K. Yamamoto, S. Kamado, T. Honma, Y. Kojima, High temperature tensile properties of ascast Mg-Al-Ca alloys, Mater. Sci. Eng. A, 509 (2009) 105-110

[20] H. Watanabe, M. Yamaguchi, Y. Takigawa, K. Higashi, Mechanical properties of Mg-Al-Ca alloy processed by hot extrusion, Mater. Sci. Eng. A, 454-455, (2007) 384-388

[21] J. H. Seo, S. K. Kim, Development trend of high temperature $\mathrm{Mg}$ alloys, J. of the Korean Foundary's Society, 28(6) (2008) 243-250

[22] J. Dong, Z. Z. Cui, Q. C. Le, G. M. Lu, Liquidus semicontinuos casting, reheating and thixoforming of a wrought aluminum alloy 7075, Materials Science and Engineering A, 345 (2003) 234-242

[23] S. Chayong, H. V. Atkinson, P. Kapranos, Thixoforming 7075 aluminium alloys, Materials Science and Engineering A, 390, (2005) 3-12

[24] S. K. Kim, Y. J. Kim, Semi-liquid forming of Magnesium Alloys, J. of the Korean Foundary's Society, 17(4) (1997) 319326

[25] P. W. Voorhees, M. E. Glicksman, Solution to the multiparticle diffusion problem with applications to Ostwald ripening-I. Theory, Acta Metallurgica, 32 (1984) 2001-2011

[26] P. W. Voorhees, M. E. Glicksman, Solution to the multiparticle diffusion problem with applications to Ostwald ripening-II. Computer simulations, Acta Metallurgica, 32 (1984) 2013-2030

[27] I. M. Lifshitz, V. V. sloyozov, The kinetics of precipitation from supersaturated solid solutions, Journal of Physics and Chemistry of Solids, 19 (1961) 35-50

[28] C. Wagner, Theorie der Alterung von Niederschlagen durch Umlosen (oswald-riefung), Zeitschrift fur Elektrochemie, 65(7) (1961) 581-591 